\title{
Carmi Syndrome in a Neonate: An Exacting Surgical Challenge
}

\author{
Ahmad A. Al Faqeeh ${ }^{1}$, Muhammad Khalid Syed ${ }^{1}$, Salman Hussain ${ }^{2}$, Talal Almas ${ }^{2}$, Mohammed Ammar ${ }^{1}$ \\ 1. Pediatric Surgery, King Fahad Hospital, Al Bahah, SAU 2. Internal Medicine, Royal College of Surgeons in Ireland, \\ Dublin, IRL
}

Corresponding author: Muhammad Khalid Syed, khalidsita@gmail.com

\begin{abstract}
Carmi syndrome is characterized by the concomitant presence of pyloric atresia and epidermolysis bullosa. Pyloric atresia routinely presents with symptoms of gastrointestinal obstruction, which include vomiting and feeding intolerance. On the other hand, epidermolysis bullosa presents with blistering skin lesions upon the slightest trauma. Due to these skin lesions, the affected patients are particularly susceptible to developing septicemia and adverse disease outcomes. We hereby delineate a case of Carmi syndrome in a neonate who was treated surgically. Postoperatively, the neonate began to deteriorate and eventually developed septicemia and passed away shortly thereafter.
\end{abstract}

Categories: Pediatric Surgery, Radiology, General Surgery

Keywords: pyloric atresia, epidermolysis bullosa, carmi syndrome

\section{Introduction}

The association of pyloric atresia (PA) and epidermolysis bullosa (EB) is extremely rare but well-documented [1]. PA has been reported to have an incidence of one in 100,000 live births and accounts for less than $1 \%$ of all gastrointestinal atresia-related disorders while the incidence of EB is one in 300,000 [2-3]. The concomitant presence of PA and EB is known as Carmi syndrome [4]. Carmi syndrome is characterized by skin fragility and blistering with minimal, or even no, trauma, along with an obstruction of the pylorus. Notably, this rare syndrome demonstrates a predilection for affecting neonates [5]. The disease carries a high mortality rate owing to its systemic manifestations such as electrolyte imbalances and septicemia. For this reason, Carmi syndrome often poses a surgical challenge [6]. We hereby delineate the case of a pre-term infant who presented with feeding intolerance and signs of skin blistering. Further diagnostic workup revealed the presence of Carmi syndrome. The patient was treated surgically but eventually deteriorated and passed away.

\section{Case Presentation}

We chronicle the case of a pre-term infant with a birth weight of 2 kilograms, born at the 33rd week of

Review began 09/16/2020 Review ended 09/17/2020 Published 09/18/2020

\section{○ Copyright 2020}

Al Faqeeh et al. This is an open access article distributed under the terms of the Creative Commons Attribution License CC-BY 4.0., which permits unrestricted use, distribution, and reproduction in any medium, provided the original author and source are credited. gestation, who presented to the neonatal intensive care unit on the second day after birth. The neonate presented with a history of feeding intolerance, which included an inability to tolerate breast and formula milk. Notably, this was on a background history of blistering skin peeling. On examination, the neonate was active, with normal vital signs. A plain abdominal radiograph revealed a single bubble sign representing a distended stomach with no distal gas presence (Figure 1). 


\section{Cureus}

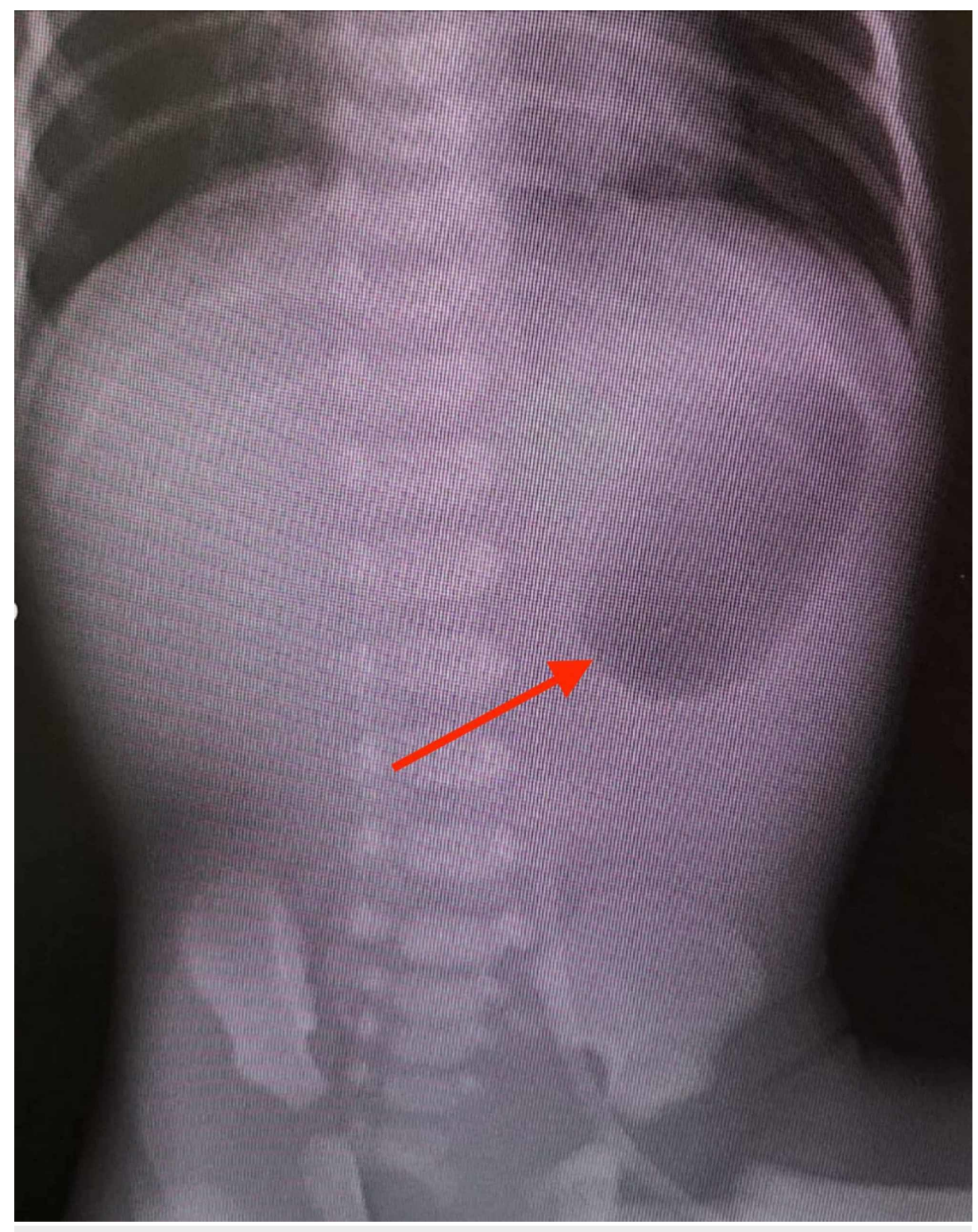

FIGURE 1: An abdominal radiograph demonstrating a single bubble sign (red arrow), which aligns with the diagnosis of pyloric atresia

Pertinently, there was no gas present in the remainder of the gut and the chest was clear bilaterally. Physical examination further divulged the presence of diffuse skin blistering, with bullae all over the neonate's limbs, and alluded to a diagnosis of epidermolysis bullosa (Figure 2). 


\section{Cureus}

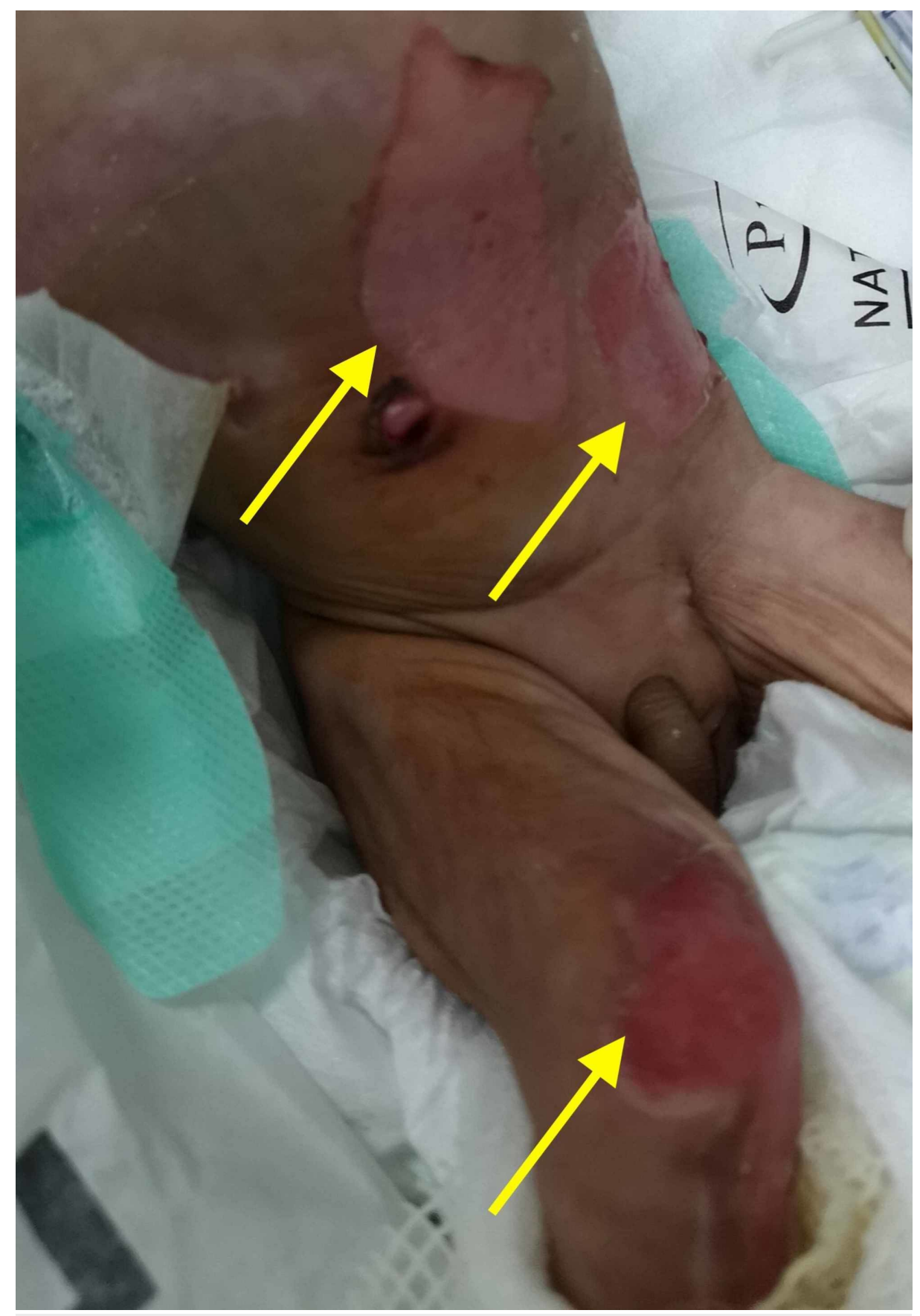

FIGURE 2: A depiction of the diffuse skin blistering (yellow arrows) as seen in the neonate

Interestingly, other associated anomalies include malformed left ear, short lower limbs, and undescended testes, which aroused the suspicion of the presence of a congenital anomaly. In addition, the mother's previous infant had passed away after suffering from the same clinical manifestations. In order to better elucidate the etiology underlying the patient's gastrointestinal symptoms, an upper gastrointestinal tract (GIT) contrast study was performed. The study revealed no contrast beyond the stomach, reaffirming the diagnosis of pyloric atresia (Figure 3). 


\section{Cureus}

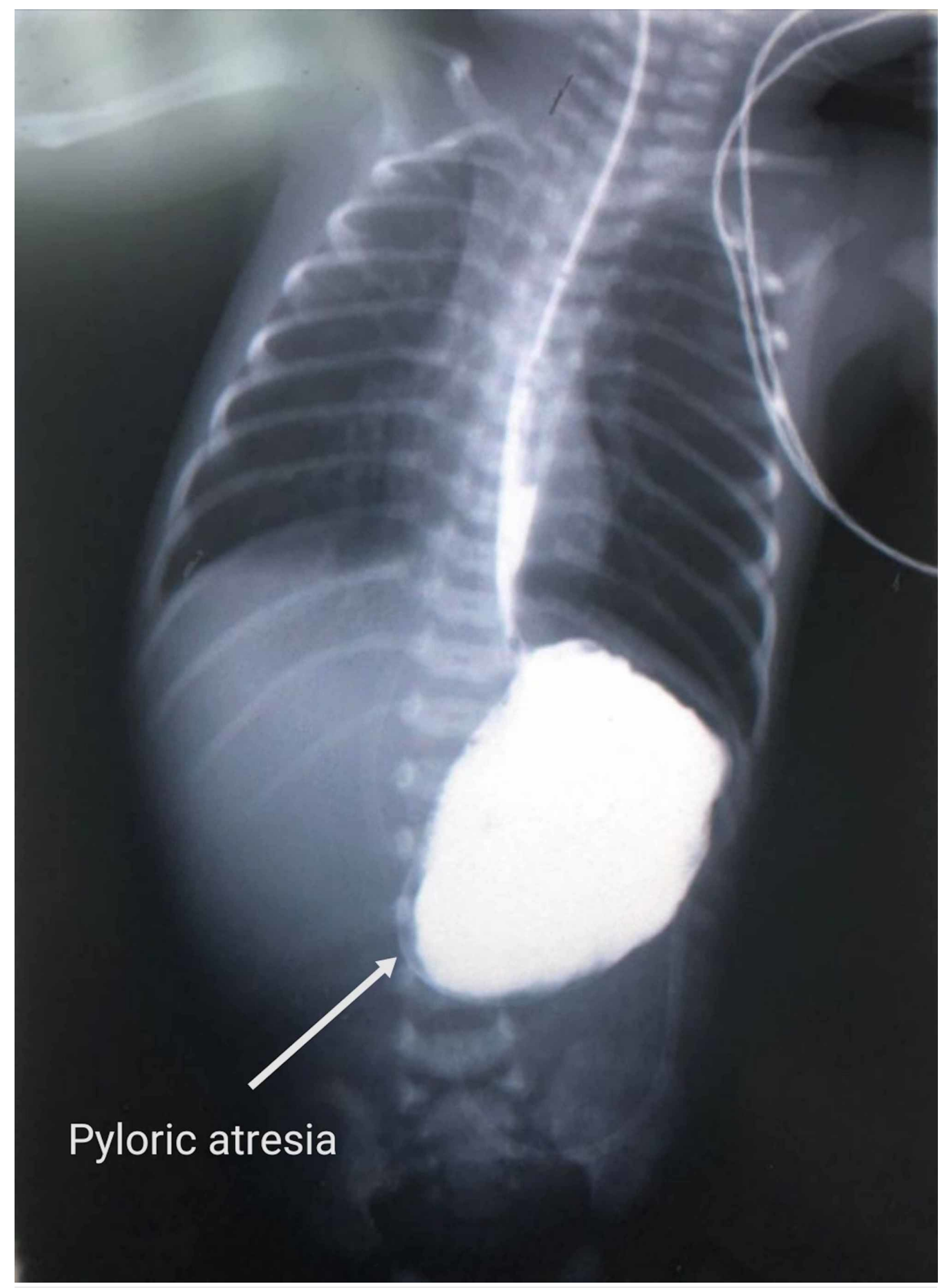

FIGURE 3: A contrast study of the upper GIT demonstrating no contrast uptake beyond the stomach and thus delineating the presence of pyloric atresia (white arrow)

GIT: gastrointestinal tract

Considering the concomitant presence of pyloric atresia and epidermolysis bullosa, a diagnosis of Carmi syndrome was made. Cognisant of the high neonatal mortality rate associated with the condition, a surgical approach was adopted. During the operation, type-2 pyloric atresia was observed, and the neonate underwent Billroth 1 operation, whereby the pylorus was excised and the distal stomach was anastomosed with the first part of the duodenum (Figure 4). 


\section{Cureus}

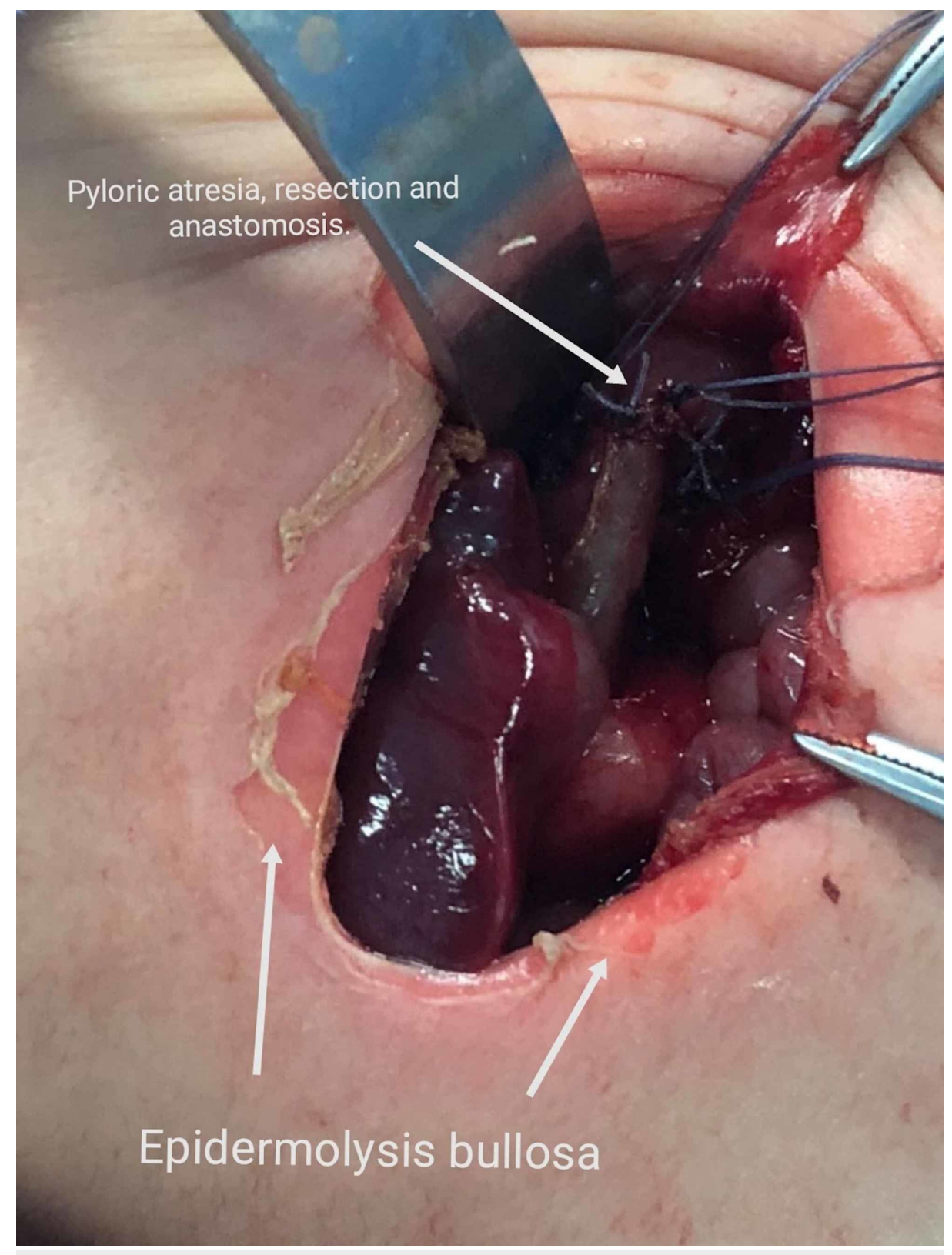

\section{FIGURE 4: Intraoperative image showing the concomitant presence of}

pyloric atresia and epidermolysis bullosa

An anastomosis between the distal stomach and duodenum was created.

In the aftermath of the operation, the neonate recovered unremarkably, with no postoperative complications. However, the neonate's health began deteriorating on the sixth day postoperatively, with worsening skin peeling that eventually culminated in septicemia. Unfortunately, the patient succumbed on the 11th postoperative day despite the administration of all possible treatment modalities, including highdose antibiotics.

\section{Discussion}

PA usually presents as non-bilious vomiting soon after birth, without abdominal distension. The plain abdominal radiograph is the gold standard imaging modality for diagnosing PA and reveals a single gas bubble that is representative of the distended stomach with no distal gas. All patients with PA should be screened for multiple anomalies, including tracheoesophageal fistulas, renal and ureteral anomalies, and EB [7]. The surgical treatment of PA depends on the anatomic variety. PA displays three anatomic variations. The variation type 1 is treated by a Heineke-Mikulicz pyloroplasty, whereas the type- 2 variation is usually treated through the removal of the atretic segment during a gastroduodenostomy. Similarly, the type- 3 variant, which is characterized by PA with a gap between the stomach and duodenum, is treated by means of 
EB encompasses a group of skin disorders characterized by blistering vesicular lesions in response to minimal or no trauma [3]. While there are no definite treatment options, the management of EB focuses predominantly on the minimization of new blister formation via appropriate dressings and infection control through the use of antibiotics and antiseptics. In addition, fluid and electrolyte replenishment, along with appropriate nutritional supplementation, remains pivotal in the management of these patients [5].

The co-existence of PA and EB is referred to as Carmi syndrome and has been reported to display an autosomal recessive inheritance pattern [9]. This could explain the presence of Carmi syndrome in both of the mother's neonates in our case. Clinically, neonates present with widespread areas of blistering and the congenital localized absence of skin (aplasia cutis congenita), as well as abdominal distention and recurrent vomiting [10]. The diagnosis of Carmi syndrome should be considered in every neonate with PA regardless of the degree of skin blistering [5]. The literature has documented a very high mortality rate and poor outcomes that can mainly be attributed to the resultant sepsis. Dank et al. reported an average survival time of 70 days among 51 patients with Carmi syndrome undergoing a surgical correction, alluding to a dismal disease prognosis owing to imminent sepsis [11]. For this reason, some studies have posited that surgical correction of PA is to be withheld in order to avoid unwarranted needle-associated suffering [12]. Nevertheless, a meticulous clinical examination, along with comprehensive history-taking, can aid in yielding a prompt diagnosis of the condition.

On the other hand, Hayashi and colleagues reported four patients with survival between 17 months and 16 years [12]. In addition, Sahebpor et al. reported five patients with the syndrome, four of which were alive at the follow-up period [2]. In our case, type-2 PA was diagnosed in a patient with Carmi syndrome and was corrected surgically through a Billroth 1 procedure. Noticeable deterioration commenced on the sixth day postoperatively, with worsening peeling of the skin. Eventually, the patient succumbed to the aggressive disease and passed away on the 11th postoperative day.

\section{Conclusions}

Carmi syndrome refers to the concomitant presence of pyloric atresia and epidermolysis bullosa and is noted to portend an exceedingly dismal prognosis in the neonatal population. Due to the diffuse and extensive skin blistering noted, septicemia routinely ensues. Emergent surgical intervention, without any preoperative delays, therefore remains focal in yielding favorable disease outcomes.

\section{Additional Information}

\section{Disclosures}

Human subjects: Consent was obtained by all participants in this study. Conflicts of interest: In compliance with the ICMJE uniform disclosure form, all authors declare the following: Payment/services info: All authors have declared that no financial support was received from any organization for the submitted work. Financial relationships: All authors have declared that they have no financial relationships at present or within the previous three years with any organizations that might have an interest in the submitted work. Other relationships: All authors have declared that there are no other relationships or activities that could appear to have influenced the submitted work.

\section{References}

1. Mithwani AA, Hashmi A, Adil S: Epidermolysis bullosa and congenital pyloric atresia. BMJ Case Rep. 2013, 2013:2013201207. 10.1136/bcr-2013-201207

2. Sahebpor AA, Ghafari V, Shokohi L: Pyloric atresia associated with epidermolysis bullosa. Indian Pediatr. 2008, 45:849-851.

3. Gupta R, Soni V, Mathur P, Goyal RB: Congenital pyloric atresia and associated anomalies: a case series . J Neonatal Surg. 2013, 2:40.

4. Sarin YK, Nagdeve NG: Carmi syndrome complicated by pharyngo-esophageal perforation . Indian Pediatr. 2006, 43:61-64.

5. Hicks TD, Singh H, Mikhael M, Shah AR: Carmi syndrome in a preterm neonate: a multidisciplinary approach and ethical challenge. Case Rep Pediatr. 2018, 2018:4548194. 10.1155/2018/4548194

6. Bıçakcı U, Tander B, Cakmak Çelik F, Arıtürk E, Rızalar R: Pyloric atresia associated with epidermolysis bullosa: report of two cases and review of the literature. Ulus Travma Acil Cerrahi Derg. 2012, 18:271-273. 10.5505/tites.2012.13284

7. Okoye BO, Parikh DH, Buick RG, Lander AD: Pyloric atresia: five new cases, a new association, and a review of the literature with guidelines. J Pediatr Surg. 2000, 35:1242-1245. 10.1053/jpsu.2000.8762

8. Ilce Z, Erdogan E, Kara C, Celayir S, Sarimurat N, Senyüz OF, Yeker D: Pyloric atresia: 15-year review from a single institution. J Pediatr Surg. 2003, 38:1581-1584. 10.1016/s0022-3468(03)00565-7

9. Chung HJ, Uitto J: Epidermolysis bullosa with pyloric atresia. Dermatol Clin. 2010, 28:43-54. 10.1016/i.det.2009.10.005

10. Lin AN: Pyloric atresia and epidermolysis bullosa. Pediatr Dermatol. 1997, 14:406-408. 10.1111/j.15251470.1997.tb00995.x

11. Dank JP, Kim S, Parisi MA, Brown T, Smith LT, Waldhausen J, Sybert VP: Outcome after surgical repair of 


\section{Cureus}

junctional epidermolysis bullosa-pyloric atresia syndrome: a report of 3 cases and review of the literature. Arch Dermatol. 1999, 135:1243-1247. 10.1001/archderm.135.10.1243

12. Hayashi AH, Galliani CA, Gillis DA: Congenital pyloric atresia and junctional epidermolysis bullosa: a report of long-term survival and a review of the literature. J Pediatr Surg. 1991, 26:1341-1345. 10.1016/00223468(91)90616-2 